\title{
The Impression of Alcohol Advertising on Consumption among Adolescents in Selected High Schools in the Eastern Cape, South Africa
}

\author{
Clifford Kendrick Hlatywayo
}

University of Fort Hare, Alice, South Africa vakendie@gmail.com

Lungisani Moyo

University of Fort Hare, Alice, South Africa lungie06@gmail.com

00. Osunkunle

University of Fort Hare, Alice, South Africa OoOsunkunle @ufh.ac.za

Doi:10.5901/ajis.2014.v3n1p347

\section{Abstract}

There is a high rate of alcohol consumption among adolescents in South Africa, especially high school leaners. The study explored the extent to which alcohol advertising impacts on adolescents focusing on selected high Schools in the Eastern Cape Province, South Africa. Results of this study revealed that most adolescence who end up consuming alcohol have been mostly exposed to alcohol advertising, although there are other contributing factors such as, the influence of friends, peer pressure and family problems. It was also revealed in this study that alcohol advertising makes adolescence aware of different brands. This information ultimately makes students feel connected to alcohol advertising, thereby leading them to consuming alcohol.

Keywords: alcohol, adolescent, abuse, high school

\section{Introduction}

Youths and the South African government are battling against the advertising and consumption of alcohol (Mandela, 1994). Drinking is portrayed as normal behaviour with no adverse effects and consequences by advertisers (Strasburger, 2001). Most techniques used by media in the advertising of alcohol such as sexual imagery and celebrity endorsements are argued to be appealing to the youth (Grube, 2004). Alcohol consumption is normalised by promoting positive expectancies such as consumption with attractive symbols, role models and outcomes, (Austin \& Hust, 2005; Chen, Grube, Bersamin, Waiters \& Keefe 2005). Globally, alcohol is a heavily advertised product (Endicott, 2005) resulting in increasing exposure to underage youth (Centre on Alcohol Marketing and Youth, 2003).

Endicott (2005) notes that marketing of alcohol to young people is crafted to mirror, express dominant representation of youth culture and lifestyles. Caswell and Maxwell, (2005) distinguished market segmentation is used in the alcohol industry to ensure significant amounts of advertising are placed where youth are more likely to be exposed to it than adults.

Shand, Gates, Mattick and Fawcett, (2003) contend that alcohol is a form of recreation and drink with the deliberate intention of becoming intoxicated by youth. Coleman and Cater, (2005) further suggests that young people do not classify themselves as binge drinkers, despite being identified as such according to regular, weekly consumption levels.

This study therefore seeks to look at the impacts of alcohol advertising and consumption on adolescents and evaluate how this improve or further complicate their lives. This study is essential as the adolescents form a very important part of any nation's population and the foundation of tomorrow's work force. This research seeks to make a sound contribution towards productive arguments in justifying how alcohol advertising leads to consumption by adolescents. Mass communication theories recognize advertising as a tool that makes consumers aware of many 
products (O'Guinn, 2005). This research seeks to evaluate among other things why adolescence consume alcohol and come up with practical recommendations towards solving the arguments associated with existing alcohol advertisements and alcohol consumption by adolescents.

\section{Research Questions}

The following research questions were formulated:

- What are the factors that motivate adolescents in the selected high schools to consume alcohol?

- Does alcohol advertising have any impacts on the view of students towards alcohol consumption?

- What is the impact of alcohol advertising and consumption on the social behaviour of High School students?

\section{Literature Review}

Agostinelli and Grube, (2002) identified a close positive relationship to views on drinking, increased intentions to drink as an adult and increased drinking behaviour among youth due to attention to and liking of alcohol advertising. Calfee \&Scheraga, (1994); Stacy et al., (2004); Chen et al, (2005); Ellickson et al, (2005), Collins et al, (2007); Fisher et al., (2007) found the association between advertising exposure and drinking on adolescence i.e., the effects of media on the behaviour and lifestyles of adolescence. Ellickson, Collins, Hambarsoomians, \& McCaffrey, (2005); Hanewinkel \& Sargent, (2007); Henriksen, Feighery, Schleicher, \& Fortmann, (2008); McClure, Dal Cin, Gibson, \& Sargent, (2006); Sargent, Wills, Stoolmiller, Gibson, \& Gibbons, (2006) support that alcohol advertising has the power to influence adolescents' drinking behaviours and that there is a positive effect between exposure to alcohol advertising and the initiation or reinforcement of alcohol consumption.

This is achieved through direct targeting of a particular age group within a particular society, thereby having a direct impact on the economy, society, the national and international policies of a wide range of actors, including Governments, International Organizations, Business, Labour and Civil Society (Martin et al., 2002). Endicott, (2005) also noted that alcohol is among the most heavily advertised products worldwide resulting in increasing exposure to underage youth.

Empirical evidence points out to high exposure levels of alcohol advertising containing appealing elements to children and underage youth. These vulnerable audiences are directly targeted marketers thereby increasing the likelihood of many such elements contained in alcohol advertisements by children and youth (Chung et al., 2010; Fielder, Donovan; Ouschan, 2009; Ringel, Collins; Ellickson, 2006; Winter, Donovan; Fielder, 2008).

The United States requires that more than $50 \%$ of the exposed audience be over 21, however, beer advertisers have no restrictions on the use of sports celebrities. Centre on Alcohol Marketing and Youth (2002) found that in 2001, advertisers delivered $45 \%$ more beer advertising to youth than to adults in magazines when they examined the exposure of the youth to alcohol advertising in magazines, on television and on radio in New York.

World Health Organization, (2007) substantiated that alcohol consumption and its related harms are a serious public health issue for many countries. Babor et al., 2003 also distinguished that young people are particularly susceptible to alcohol related harms and risk of disease and injury, and social consequences relates to both the volume of consumption and pattern of alcohol use.

\section{Methodology}

A descriptive methodology was adopted; a sample of 40 participants per school was adopted. Three high schools formed the population of the study; responses were collected from grade 10-12 leaners. There were 120 respondents. A qualitative approach utilised so as to gain insight into the phenomenon under investigation. Statistical analysis involved Content analysis which is a descriptive representation of the findings.

\section{Empirical Results}

\subsection{Participant's perception on alcohol companies intentionally target the youths.}

Respondents were asked their perceptionon alcohol companies intentionally targeting them when they use television programmes such as prominent soapies, celebrities and sport matches to promote their products. Most respondents, 78 
(65\%) shared the sentiment that companies do target the youths. This is as most adverts or commercials of alcohol intensified their advertising campaign during prime time viewing. The other respondents $42(35 \%)$ were of the notion that exposure to alcohol advertisements depends on the individual.

Leaners saw a link between alcohol companies and the people who design television programmes. They cited that they think alcohol companies do target the youth during certain television programs especially during their favourite soapies such as Rhythm City, Isidingo and Generations and sport games.

\subsection{Exposure to alcohol advertisements}

Respondents were asked whether they were exposed to alcohol advertising, 102(85\%) were exposed as compared to 18 $(15 \%)$ who were not. Evidence from their responses showed that adolescents are exposed to alcohol advertising. This was confirmed in the follow up question, where respondents were asked to identify any brand name (alcohol) and message contained in those advertisements they have seen where names and slogans are not blocked out. This in a way signifies their level of exposure to alcohol advertisements. Even those who were not exposed to alcohol advertising were at least aware of one to two "slogans" for beer. All the focus group discussion participants acknowledged that they are in one way or the other exposed to alcohol advertisements.

\subsection{Mediums used to advertisements alcohol}

Six types of media were examined to find out the forms of media in which respondents were exposed. The dominant forms of media were television (TV),radio, newspaper, magazine, and billboard. Responses indicated that 51(42.5\%) were exposed to alcoholadvertisements on television;6 (5\%) of the participants were exposed to alcohol advertisements through radio;9 (7.5\%) of the total participants were exposed to alcohol advertisements through newspapers; billboards contributed 12(10\%); 4 (2.5\%) of the participants indicated that they get their information from the magazines; 38 (32.5\%) said that they saw the alcohol advertisements from all the five mediums.

Evidence confirmed that those who are more exposed to alcohol advertisements are the ones consume alcohol after seeing the different advertisements. The majority of participants who watch television are found to be the ones who decide to drink and most of them are from the age group of 18-20 years. The results indicated a relationship between exposure and intension to consume alcohol.

To support the above the following dominant responses were gathered:

"..because when you are exposed to something for a long period of time, you finally get convinced that it is the right thing to do".

"Drinking is a personal interest and does not need me to see an advert in order for me to start drinking"

"When you see an alcohol advertisement and the way those who advertise it enjoy, you wish it was you and this will lead us then to go and experiment in order for us to see if we can have the same fun."

"If afforded time and opportunity, I would like to also have that much fun as the people who advertise beer on television".

"Anyone has a right to choose and the issue of what is acceptable or not cannot come in place when it comes to alcohol consumption ....., maybe if it was something like committing a crime then one can say it is not a good thing."

"When you see someone beautiful on television advertising alcohol you will be tempted and want to go and see if there are any beautiful ladies in taverns".

"It makes you believe that you will drink alcohol and get to socialize with beautiful women",

"When you see all those beautiful women in the advertisements, it makes you think that if you drink alcohol you will get beautiful ladies".

"..In as far as I am concerned, I have so far not yet seen a person who is drinking alone. All those people who drink beer in alcohol advertisements seem to have a lot of friends. So coming to the issue of drinking and having friends, I think for me, you need to drink in order for you to have a lot of friends."

"As for me, I would want to appear on television playing soccer or maybe advertising cars."

"Even if you do not want to be exposed to alcohol, you end up being a victim of it."

"For some of us who follow soccer and are inspired by celebrities, we tend to also follow their live style as we see them as role models. If you look for example, the life styles of the legends like Jabu Pule, who drink as if there is no tomorrow and even admit to the press that he has alcohol problems...even our youth President Julius Malema admitted on national television that he do drink a lot when he was interviewed by Deborah Patta on $3^{\text {rd }}$ degree".

"Those adolescents who drink beer do so because of peer pressure and they want to look as if they are cool in front of their friends but when they are alone, they regret drinking".

"As adolescents, we just drink for fun and some of us like me are just experimenting, we want to see if what is shown on television is true, that is you can be a champion if for example you drink 'certain brands', that is why we do drink" 


\section{Conclusion}

The study results also showed that 93 (77.5\%) of the respondents indicated that they do consume alcohol, 27 (22.5\%) of the respondents indicated that they do not drink alcohol.The results indicated adolescents' alcohol consumption, as well as other habits within the social environment which encourage alcohol consumption. The results of the study were consistent with that of literature; Engels \& Knibbe, (2000) who experimenting, problems in human relations, family problems, an alcoholic parent asother the factors that lead to alcohol consumption; Connolly et al., (1994) looked into the subject matter using the associations between age and gender, they no relationship between advertising media with alcohol initiation (after controlling for other factors).

Lorente et al., (2004) purported that it was possible that other factors play a more important role in influencing alcohol initiation among males and younger females than does advertising. Advertising appears to influence the rate and quantity which the young population consumes (Gordon et al., 2010; Anderson et al., 2009).

Shebeens, billboard advertising alcohol were observed to be within 100 meters from the respective schools. There was also a lack of parental guidance and role models from the local communities. The findings of the study are essential to policy makers and education departments as they can ensure that places of alcohol consumption are isolated from education institutions as a control measure to deter youth.

\section{References}

Agostinelli, G., and Grube J.W. (2002). Alcohol counters Advertising and The Media. Alcohol Research and Health, 26, 15-21.

Anderson, P., de Bruijn A., Angus A., Gordon, R. and Hasting, G. (2009). Impact of alcohol advertising and media exposure on adolescent alcohol use: A systematic review of longitudinal studies. Alcohol and Alcoholism, Advance Access, 1, 15.

Austin, E.W., and Hust, S.J.T. (2005). Targeting adolescents? The content and frequency of alcoholic and non-alcoholic beverage ads in magazine and video formats November 1999-April 2000. Journal of Health Communication, 10, 769-785.

Babor T.F., Caetano, R, Casswell S., Edwards, G., Giesbrecht, N., Graham, K., Grube, J.W., Gruenewald, P.J., Hill, L., Holder, H.D., Homel, R., Österberg, E., Rehm, J., Room, R. and Rossow, I. (2003). Alcohol: No Ordinary Commodity. Research and Public Policy. Oxford, Oxford Medical Publication, Oxford University Press.

Casswell, S. and Maxwell, A. (2005). Regulation of Alcohol Marketing: A Global View Journal of Public Health Policy, 26, 343-358.

Calfee, J.E., and Scheraga, C. (1994). The influence of alcohol advertising on alcohol consumption: A literature review and an econometric analysis of four European nations. International Journal of Advertising, 13, 287-310.

Centre on Alcohol Marketing \& Youth (CAMY) (2002). Exposure of African-American Youth to Alcohol Advertising. Washington, DC: The Centre on Alcohol Marketing and Youth.

Chen, M., Grube, J.W., Bersamin, M., Waiters, E. and Keefe, D.B. (2005). Alcohol advertising: What makes it attractive to youth. Journal of Health Communication, 10, 553-565.

Chung, P., Garfield, C., Elliott, M., Ostroff, J., Ross, C., Jernigan, D., Vestal, K., and Schuster, M. (2010), "Association between adolescent viewership and alcohol advertising on cable television", American Journal of Public Health Affairs, 100, 555-562.

Coleman, L., and Cater, S. (2005). Under age "risky" drinking: Motivations and outcomes. York, Joseph Rowntree Foundation.

Collins, R.L., Ellickson, P.L., McCaffrey, D., and Hambarsoomians, K. (2007). Early Adolescent Exposure to Alcohol Advertising and its Relationship to Underage Drinking. Journal of Adolescent Health, 40, 527-534.

Connolly, G.M., Casswell S., Zhang, J.F. (1994). Alcohol in the mass media and drinking by adolescents: a longitudinal study. Addiction 89:1255-63.

Endicott, R. C. (2005). "Advertising Age's 19th Annual Global Marketing." Advertising Age November, 14, 1-53.

Engels, R.C. and Knibbe, R.A. (2000). Young people's alcohol consumption from an European perspective: risks and benefits. European Journal of Clinical Nutrition, 54 S52-S55.

Ellickson P. L., Collins, R.L.,Hambarsoomians K., and McCaffrey, D. F. (2005). Does alcohol advertising promote adolescent drinking? Results from a longitudinal assessment. Addiction, 100, 235-46.

Fielder, L., Donovan, R. and Ouschan, R. (2009), "Exposure of children and adolescents to alcohol television advertising on Australian free-to-air television", Addiction, 104, 1157-1165.

Fisher, L.B., Williams Miles, I., Austin, B. (2007). Predictors of initiation of alcohol use among United States adolescents, findings for a prospective cohort study. Archives of Paediatrics \& Adolescent Medicine, 161, 959-966.

Gordon R., Hastings, G., and Moodie, C, (2010) Critical social marketing - the impact of alcohol marketing on youth drinking: qualitative findings. International Journal of Non-profit Voluntary Sect Mark, 15,265-75.

Grube, J. W. (2004). Reducing Underage Drinking: A Collective Responsibility. National Research Council (US) and Institute of Medicine (US) Committee on Developing a Strategy to Reduce and Prevent Underage Drinking. Washington (DC): National Academies Press (US).

Hanewinkel, R, Tanski, S. E., Sargent, J. D. (2007). Exposure to alcohol use in movies and teen drinking in Germany. International Journal of Epidemiology. 36, 1068- 1077. 
Henriksen, L., Feighery, E.C., Schleicher, N., and Fortmann, S.P. (2008). Receptivity to alcohol marketing predicts initiation of alcohol use. Journal of Adolescent Health, 42, 28-35.

Lorente, F. O., Souville, M., Griffet, J. and Grélot L. (2004) Participation in sports and alcohol consumption among French adolescents. Addictive Behaviours, 29, 941- 946.

Martin, S., Snyder, L.B., Hamilton, M., Fleming-Milici, F., Slater, M.D., Stacy, A., Chen M- J., and Grube, J. W. (2002). "Alcohol Advertising and Youth", Alcohol Clinical and Experimental Research, 26, 900-906.

McClure, A.C., Dal Cin, S. Gibson. J., and Sargent. J.D. (2006). Ownership of alcohol- branded merchandise and initiative of teen drinking. American Journal of Preventive Medicine, 30, 277-283.

Nelson Mandela inaugural address in parliament. (1994). Available: http://www.info.gov.za/view/DownloadFileAction?id=70476 [Accessed on 03, August, 2010]

O'Guinn, T.C, 2005. Advertising and integrated brand promotion, 4th Ed .Mason, Ohio: South-Western

Ringel, J.S., Collins, R.L., Ellickson, P.L. (2006). Time trends and demographic differences in youth exposure to alcohol advertising on television. Journal of Adolescent Health, 39, 473-480.

Sargent, J.D., Wills, T.A., Stoolmiller M., Gibson, J., and Gibbons, F.X. (2006). Alcohol use in motion pictures and its relation with teen drinking. Journal of Studies on Alcohol. 67, 54-65.

Shand, F., Gates, J., Fawcett, J. and Mattick, R. (2003). Guidelines for the treatment of alcohol problems. Sydney: National Drug and Alcohol Research Centre.

Stacy, A.W., Zogg, J.B., and Unger J. B. (2004). Exposure to televised alcohol ads and subsequent adolescent alcohol use. American Journal of Health Behaviour, 28, 498-509.

Strasburger, V.C. (1995). Adolescents and the Media: Medical and Psychological Impact. Thousand Oaks, CA: Sage.

Winter, M.V., Donovan, R.J. \& Fielder, J. (2008). Exposure of children and adolescents to alcohol advertising on television in Australia. Journal of Studies on Alcohol and Drugs; 69, 676-683.

World Health Organization (2007). World Health Organization Expert Committee on Problems Related to Alcohol Consumption. Geneva: World Health Organization. 
